Article

\title{
Unconventional Approach for Prevention of Environmental and Related Social Risks: A Geoethic Mission
}

\author{
Francesca Romana Lugeri ${ }^{1, *}$, Piero Farabollini ${ }^{2, *}$ (D) , Vittorio Amadio ${ }^{3}$ and Roberto Greco 4 \\ 1 ISPRA Istituto Superiore Protezione e Ricerca Ambientale, Via V. Brancati 48, 00144 Roma, Italy \\ 2 University of Camerino, Via Gentile Terzo da Varano, 62032 Camerino, Italy \\ 3 University Mediterranea, 89124 Reggio Calabria, Italy; vittorio.amadio@unirc.it \\ 4 Instituto de Geociências-Unicamp, R. João Pandiá Calógeras, 51, Campinas CEP 13083-870, Brazil; \\ robertogreco01@yahoo.it \\ * Correspondence: francesca.lugeri@unicam.it (F.L.); piero.farabollini@unicam.it (P.F.)
}

Received: 24 November 2017; Accepted: 1 February 2018; Published: 5 February 2018

\begin{abstract}
Some natural events are considered catastrophic for their damaging effects on society; however, many of these effects are due more to inappropriate management of the environment rather than the event itself. In order to prevent the continuation of the occurrence of such pernicious situations, it is necessary to spread the knowledge of natural mechanisms so that the general public becomes aware of the dynamics that characterize our planet's balance. To this aim, we argue it is indispensable to find, create and test new methods of communication in order to reach a wide audience in an understandable way. We believe in science popularization as an ethic mission: the proposal is dedicated to those Outdoor Sports that take place in the landscape, considered as an ideal vector of information, as people develop curiosity and motivation to learn about natural history. Our study focuses particularly on cycling because of its popularity as well as for its close ties to the environment.
\end{abstract}

Keywords: risk; prevention; landscape; communication; sport; ethic

\section{Introduction}

Geoethics. Let us start from the definition of the key term: ethics are a system of moral principles; moreover, ethics are defined as the rules of conduct recognized with respect to a particular class of human actions or a particular group or culture.

Let us reflect on a further fundamental concept: Nature is defined as the foundation of existence, in its physical and biological settings, or as a set of characters in a certain region still not changed by "Civilization".

Integrating these two essential concepts, it is almost automatic to see clearly how deep and innate the link between Geology and Ethics is, and how to develop something more than a naturally ethical behavior in practicing, with the goal of recognizing and reaching strategically ethical objectives; first of all, survival itself.

Starting from these encyclopedic definitions, this paper aims to provide a contribution to the world of Geoethics, a rising world extremely rich in new perspectives [1-3]. In parallel, the future of our planet appears deeply linked to Geoethics. The extraordinary interest in this new field of research, halfway between philosophy and Geoscience, with a strong appeal to translate into actions the results of those reflections, testifies the social need of such innovative discipline.

Geoethics investigates "the ethical, social, and cultural implications of geoscience research, practice, and education, representing a new way of thinking about and practicing Earth sciences" [4]. 
New challenges for geoscientists: all of us have "new skills and tasks linking different disciplines, applying different methodological procedures and technologies, and facing new scientific, social and cultural challenges, from micro- to macro-scale studies" [5].

In this paper, we would like to contribute to the Geoethics discussion from the Italian experience in sharing with the general public some of the scientific concepts which are key to reaching a common consciousness of natural hazards and related social risks, in order to achieve a concrete risk prevention: in a country like Italy, this appears to be the main strategic, ethical objective.

We aim to propose some unconventional ways in interpreting the role of geologists referring to Ethics (after all, that is the core concept in everyone's life), starting from ideas, experiences, results achieved by the Geoethics research community [6-10].

Summarizing, the key concepts for the start of our ethics project and its subsequent development within the social framework are: prevention, public health, social wellbeing, knowledge.

Prevention is a combination of knowledge, conscience, and action. Preventive behaviors, referring to environmental risk sensu lato, can be considered public health tools; in fact, public health is commonly linked to the occurrence of epidemics and contagion: actually, it includes problems such as hydro-geological and seismic risk.

The environment impinges on individual and social well-being. Knowledge of natural mechanisms must be spread so that the general public becomes aware of the dynamics that characterize our planet's balance.

The paper starts from a synthetic overview of the theoretical premises, aiming to examine the role of knowledge in the so-called Risk Society [11]. The related concept of communication is approached, also referring to the tools available thanks to contemporary technology.

The focus of this paper is the role of the Landscape in communicating Earth Sciences, using the landscape element to foster curiosity of knowledge related to Earth Science, as a possibility for open channels of communication and information, especially referring to the binomial risk/resource model inherent to most of the land settings in Italy. The core of the proposed work lies in accomplishing new ways of communicating Sciences, aimed at the widest possible public, in order to achieve the ethical objective of safe life by risk prevention.

The Giro d'Italia is an annual multiple-stage bicycle race held in Italy, in May, for more than a century. The GeoloGiro, an original project realized in Italy, is here explained by two stages of the Giro 2013, particularly significant in showing the above-mentioned dualism. Experiences and results are synthesized in the final part of the work, considering these components as a transitory step, in a long path towards a concrete enhancement of social behavior. This paper can be considered halfway between an opinion piece and a scientific paper: it is based on scientific foundation and concerns concrete experiences. At the same time, it is a vision, a wide-ranging idea: in this sense, it is unconventional in addition to the proposed contents. We choose to emphasize the set of ideas, their originality, the potential of the informative campaign, especially considering that other cultural topics (history and economy for example) are habitually inserted in the TV live transmission of the Giro and the other European cycling races as well. Or, as told before, themes such as medical prevention of diseases or epidemics are hosted through TV transmission. It seems incredible that Earth Sciences have been so long kept far from live transmission compared with those sports that are performed into the natural environment. The aim of the project and its research style follow from the International Year of planet Earth (IYPE): a joint initiative by UNESCO and the International Union of Geological Sciences (IUGS). “The International IYPE aims to capture people's imagination with the exciting knowledge we possess about our planet, and to see that knowledge used to make the Earth a safer, healthier and wealthier place for our children and grandchildren. The IYPE aims to ensure greater and more effective use by society of the knowledge accumulated by the world's Earth scientists. The IYPE's ultimate goal of helping to build safer, healthier and wealthier societies around the globe is expressed in the Year's subtitle 'Earth science for Society'" [12]. Moreover, the United Nations has proclaimed 2017 as the International Year of Sustainable Tourism for Development, "in recognition of the tremendous potential 
of the tourism industry, which accounts for some $10 \%$ of the world's economic activity, to contribute to the fight against poverty and foster mutual understanding and intercultural dialogue, which are at the heart of UNESCO's mission" [13]. In its Multiannual Work Programme 2014-2018, the EEA (European Environmental Agency, Copenaghen, Denmark) highlights the need for a transition towards a more sustainable society, realizing a scoping study on the links between public communication, environment policy implementation and behavioural science; it explores-and aims to develop-the role of public communication to improve the implementation of environmental legislation and to contribute to this debate by bringing communications, environment and behaviour closer [14]. We try to transmit the responsibility of everyone in landscape protection and enhancement, (Landscape convention) and the participation in territorial management (participative democracy) $[15,16]$.

\subsection{Sharing Knowledge: An Ethic Objective}

Mankind, throughout history, has become aware of the surrounding environment, of which he himself is part: knowing the environment in which one lives, is a process of fundamental importance for the survival itself: today more than ever it assumes strategic importance. The difficult path towards knowledge has been characterized, at various times, by different approaches, conditioned by the availability of tools and resources, as well as by the particular historical social, political phases. At last, today shares the need of an integrated, holistic knowledge, taking into account all the aspects that make up the complexity of the environment, as shown in the real life of our planet. The diffusion of scientific heritage, using topics well known and appreciated, may represent one of the new goals for the Territorial Sciences. From an examination of some of the dramatic events that have occurred in Italy related to the geo-environmental setting of the country and to the effects of the interaction with anthropic pressure, there emerges the need to provide the general public with correct and clear information on the complex scenario characterizing this-as well as another-country. Public participation geographic information systems (PPGIS) can be considered a natural evolution of GIS, as a tool in participatory democracy. The strong potential of such instrument is related to the multipurpose function, being made of different disciplines, different sectors, crossed and integrated thanks to appropriate GIS architectures [17,18].

\subsection{Risk and Hazard}

The concept of risk is used widely when one talks about catastrophes, but its use is not always clear and unequivocal. In order to avoid ambiguity, the concept of risk can be expressed in analytic terms by way of a formula that ties danger, vulnerability, and exposed value.

$$
\text { Risk }=\text { danger } \times \text { vulnerability } \times \text { exposed value }
$$

The term danger expresses the probability that in a certain area, a destructive event of a certain intensity within a certain time frame (that can be the "time lapse") will take place. Danger is therefore a function of the frequency of an event. Vulnerability, on the other hand, indicates the predisposition of a certain "environmental component" (human population, buildings, services, infrastructure etc.) to bear the effects of an event depending on its intensity; it expresses the degree of losses of a given element or a series of elements resulting from the occurrence of an event of a certain intensity. The exposed value or exposure indicates the element that has to bear the event and can be expressed by the number of human inhabitants or by the value of the natural and economic resources present that are exposed to a certain danger. Experience teaches us that tackling the subject of the prevention of risk and protection from danger (the avoidance of exposure) is very difficult [19]. The traditional approach used in Italy until now in addressing these themes has not come up with results worthy of mention. To turn disasters into a show in the media as often happens in "peace time", has the effect of distancing the audience from possible future situations. To talk about them immediately following a catastrophic event instead induces an effect of surreality that can lead to anger and bewilderment. Neither of 
these two communicative styles provides effective training for adopting measures of prevention and self-preservation. Instead, what is needed is a communicative strategy that informs the public of the characteristics of a territory (understood as a natural and cultural environment) and the relative operative dynamics, just as one should understand the anatomy and physiology of one's own body, when still healthy, in order to manage and protect it in the best possible way [20].

\subsection{Knowledge and Diffusion of Information}

Landscape plays a key role in the communication of environmental sciences, and the same can be said for knowledge processes: it is the object of human perceptions, the aspect of the environment which people perceive and with which people interact. Landscape is the result of the endogenous and exogenous activities that mold the Earth's surface: even at different scales, the processes and the rocks, as elements of the landscape, condition the evolution of the environment and form the base of spatial-temporal development of a region [19]. Shape is synthesis, as Aristotle teaches us: following an Aristotelian approach in studying nature, it is natural to read the land features as the expression of the geological and environmental settings of a land [20]. Today there is an awareness that a holistic approach to knowledge has much to offer by taking into consideration all aspects that constitute the complexity of nature [19]. Moreover, it is indispensable to balance individual psycho-physical development with that of the natural environment: interaction between the individual, community, and society with the environment is articulated between opposite poles: risk and resources. For this reason, such a complex process must be based on knowledge.

\subsection{Communication, Sport and Public Health}

The importance of sport for public health is examined from an unusual angle in our study; sporting competition, given its entertainment value and popularity, has an excellent communicative potential that can be used successfully in communicating messages about prevention. Similar models have been used in the past such as the campaign for the prevention of tumours (Giro d'Italia 2012 Fondazione Giovanni Veronesi) and the promotion of healthy eating. In our study, it is an important sporting event that becomes the means of communication in the field of prevention of natural disasters and in the protection from related risks. The connection of a sport such as cycling to the land, the duration of the races, as well as the vastness of the territory covered provide a unique opportunity to disseminate useful information for the protection of individuals/communities/society exposed to dangers connected to natural events of exceptional intensity.

\section{Materials and Methods}

\subsection{Landscape: An Ethic Tool for Knowledge}

Landscape plays a key role in this since it is the aspect of the environment which people perceive and with which people interact. It is the object of human perceptions as well as the result of the endogenous and exogenous activities that mold the Earth's surface [20]. The main goal of a complete Landscape analysis consists of identifying and monitoring the natural environment, thanks to models obtained by GIS technology: an upgradeable, multi-scale system, capable of holding a wide range of information about the physical, biotic and anthropic territory, considered both individually and in their mutual interaction and integration. A methodological approach based on these assumptions can lead to improvement of adequate tools for territorial planning and land use. The study of the landscape can be described through a series of steps, but should be understood as a process whose phases, related to different disciplines are integrated rather than simply in succession. A holistic approach requires a different point of view compared to that of the specific disciplines, and approaches closer to the natural aptitude to observation. In this sense, the study of the landscape contrasts with the fragmentation of knowledge: it requires a collective action, in which everyone is aware of putting their discipline in the service of a cognitive strategy. At the same time, it offers new perspectives in the transmission 
of knowledge, while opening a dialogue between technicians, decision makers/politicians, citizens. Landscape is everywhere, but it needs to be understood and recognized as a heritage; at the same time it needs to be protected, in order to become a resource: the quality of landscape impinges on individual and social well-being; moreover, as ratified in the European Landscape Convention (2000) "Landscape is everywhere and is an essential element of quality of life and cooperates in the development of local cultures" [21]. The key role of the landscape is in its perceptive and symbolic power: the loss of landscape triggers dangerous consequences to culture and society. Interaction between the individual, community, society with the environment must be based on knowledge and experience. The geological landscape is an excellent vehicle for education about the environment and about Earth Sciences; it is a result of endogenous and exogenous activity that create and form the Earth's surface while at the same time it can be considered the result of the interaction of many natural and cultural components [22-25]. Awareness, therefore, that the Geosciences can be a powerful tool for achieving and sharing a "sense of environmental identity" deriving from an awareness of being part of an ecosystem, is obtained through knowledge and experience of and in the environment. We will illustrate various ways of studying and researching the landscape that open up new interpretations and ways of understanding landscape as an element of a system in which geology plays a primary role and acts as a catalyst to arouse emotions that otherwise would not be felt or appreciated. In this way, it is possible to communicate and spread information about natural hazards and raise the public's awareness about natural hazards and risks. In this study, we will focus in cycling for creating a new (unconventional) way in communicating Earth Science, but this concept could be extended to other outdoor activities such as hiking, orienteering, climbing, and last but not least, sailing, which, especially in Italy, is a necessity and an instrument of sustenance as well as a sporting discipline, and one that is carried out only by the elite of society. We start analysing cycling due to its widespread popularity and its close ties with the landscape. Cycling is an excellent sport, mostly performed in the environment "en plain air", loved and practiced universally, and is increasingly becoming a means of providing independence and integration for disabled people. It is a transport solution with zero environmental impact and thus it represents a fundamental resource that contributes in those plans aiming to make smart cities possible. Moreover, as a sport that enjoys a large following at the competitive level, cycling favors the processes of identification and thus has high potential for spreading scientific information to the general public. The selected way of planning the project as well as analyzing the response of the public mostly refers to the participant observation, [26,27]. Although such a method can be considered "messy and difficult to manage" [28], it appears as one of the approaches that best fits the kind of situation lived in the Giro world. The continuous presence of the same person, all along the Giro, as a TV communicator as well as a cycling fan, created a special atmosphere, encouraging the dialogue with the public. This is the most interesting factor characterizing the experience: a direct line linking people and researcher. The same factor that has inspired the narrative style preferred in writing the papers included in this work, following the qualitative social analysis paradigm, as well as the related participant observation research, is still the best way to approach new communities, also trying to link them. Data collection, according to qualitative methods, has been carried out by following the semi-structured interview techniques. Such research paths require a full immersion of the researcher in the natural environment of the studied group, directly interacting with its members, in order to understand behaviors and motivations by identification processes.

\subsection{Environment, Society and Communication}

This period is defined as postmodern from a socio-economic point of view; as an Era it is also identified/classified as Anthropocene, a term coined by Paul Jozef Crutzen, Nobel Prize winner for chemistry in 1995, to define the first geological Era in which human activities have been able to influence the atmosphere and alter its balance [29]. It is evident that we need a new approach to the problems related to the complex context in which our planet is going beyond the critical point, especially given the serious consequences that humankind will have to endure as a result. Today, more 
than ever, an efficient and timely activation of environmental protection and public health is urgently required. A necessary step in this new direction is to create a new kind of communication that can reach a wider target audience, thus creating a conscious and responsible general public. One of the best ways to attain this goal is the popularisation of the Environmental Sciences, the first step towards a social consciousness of the processes linking environment and society [30-32]. Communication begins from the landscape, one of the keywords of this project. The shape and position of the so-called "Boot" (a nickname due to the shape of Italy) encompasses a wide variety of types of landscape, natural and man-made, concentrated in a narrow, elongated area.

\subsection{Tools}

The representation of territory through mapping and the description of different landscapes, and the visualisation of correlated images (models, photos, videos) thanks to GIS and GIS webs, provide the users with a process of recognition of landscape according to its components, which have too been identified, "discovered", and described. Moreover, the possibility of visualising an interpretive representation of reality in a spectacular way (3D modelling, animation etc.) makes GIS a particularly engaging tool and thus an effective one for educational use. In the field of spatial multimediality, virtual and augmented reality play an essential role, as multipurpose methods, powerful tools in different fields: from territorial planning to tourism, from teaching to environmental modeling. In this case, the new methodologies of analysis are developed to explore themes and to broaden the range of research. The potential of 3D models is already widely proven [29-31] and can be further developed. Among the many features of 3D, the most representative is the display of significant images: the content of information and data inherent in the model allow the users to configure systems evolution. In the field of Earth sciences, thanks to these tools, it is possible to follow the changes over time of the studied portions of the planet, from the investigable past to the present, from the present to possible future changes. The pattern of changes over time, in addition to bringing an extraordinary value to almost all fields of scientific research, is a powerful vector of information. As with GIS, the 3D tool is available at different levels of detail and complexity, so it can be effective for teaching as well as for spatial planning, or in the identification and management of resources, or risks; therefore, we can say that 3D modelling performs an effective function in scientific communication so that it could play a key role in the activation of prevention practices. It is of fundamental importance to link the modelling to reality, in order to convey the meaning of the model, not only in the spatial dimensions, but also through the diachronic one [33-37].

\subsection{GeoloGiro}

The "GeoloGiro" is a project aimed to make comprehensible to the general public (and to the athletes) the environmental setting of the landscapes crossed by the cycling race "Giro d'Italia", the most important stage race in Italy: circa 3500 km, 21 stages, in May. The project was welcomed by the organizers of the Giro RCS Eds., the Italian Cycling Federation and Rai Sport (the Italian state TV company), which have included in the live programming of each stage-"Anteprima Giro"-a short insert dedicated to offering the public a new and interesting point of view of the landscapes and the sites, linking scientific information to the competitive value of the stage. The morphology of the territory becomes a key component in the context of the race; scientific information about the geo-morphologic settings of an area is related to cultural news and to the local arts and tradition (always deeply linked to environmental conditions). In the following paragraphs, two of the most representative stages of the Giro d'Italia 2013 are explained. These stages are particularly significant, referring to the dualism risk/resource inherent in the territorial settings of a region.

\subsubsection{Vajont}

From the point of view of prevention of natural hazards, a very significant experience was the stage of 15 May 2013, "Tarvisio-Vajont", which passed through the places of the greatest Italian tragedy 50 years after the event (Erto and Casso, Belluno province, Veneto Region, NE of Italy). On 9 October 
1963, at 10.45 p.m., a huge landslide took place in the Vajont valley. A rock mass with a volume of nearly 250 million cubic meters slid from the northern slope of Mount Toc along a front of $2 \mathrm{~km}$ and rushed into the underlying artificial lake causing a huge wave, assessed at 26 million cubic meters of water. The mixture of water and rock fragments overflowing the dam situated in the Vajont ravine crashed into the lower valley. [38-40]. The result of this devastating landslide was 1909 people dead, the almost complete destruction of the town of Longarone, and considerable damage for the village municipalities of Erto and Casso. Fifty years later, the Giro d'Italia, commemorated the tragedy paying tribute to the victims (Figure 1). During the stage, a delegation of Italian geologists took part in the TV transmission, participating in a dialogue with the local community, and explaining the dynamics of the tragic event, which rather than being a natural catastrophe, was instead the result of the interaction between a natural event (the landslide) and the infrastructure placed in an inappropriate site. From a simple consideration of the name of the Mount "Toc", which in the local dialect means broken, it is clear that the damages were caused by the presence of the dam [40,41]. Reflecting on this case, it becomes painfully clear the absolute necessity of shared knowledge of the area where people live, that could assume a space-time evolution, intervening in a preventive way, thus avoiding an emergency.

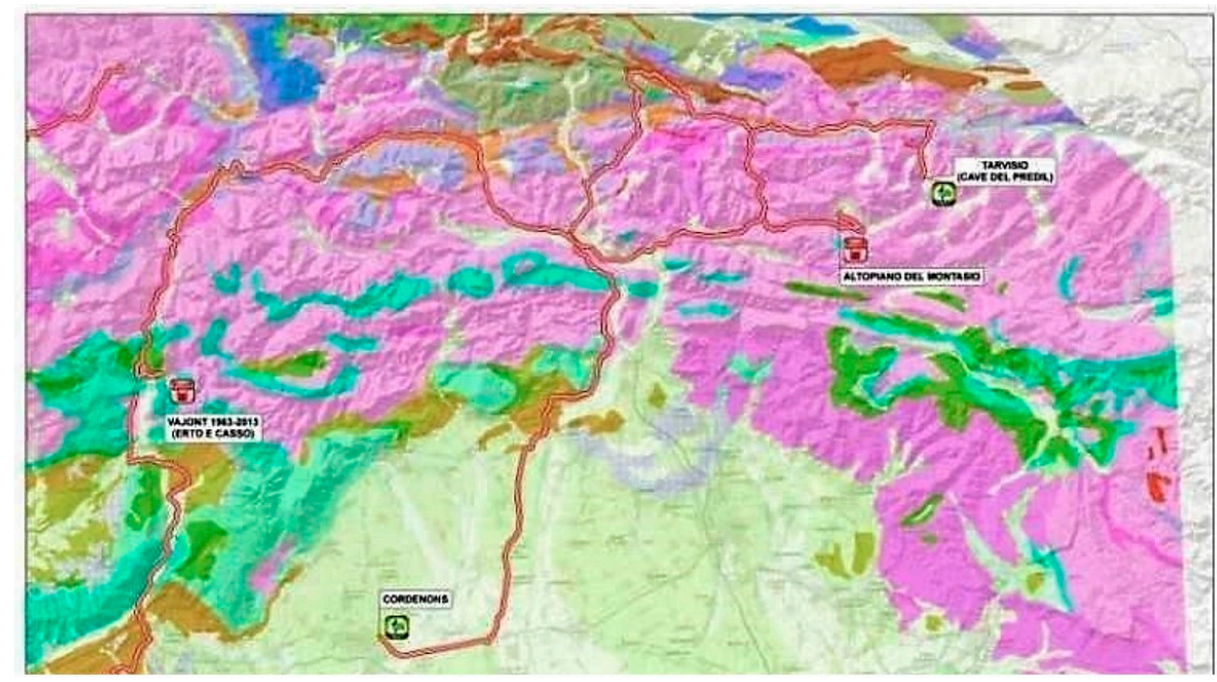

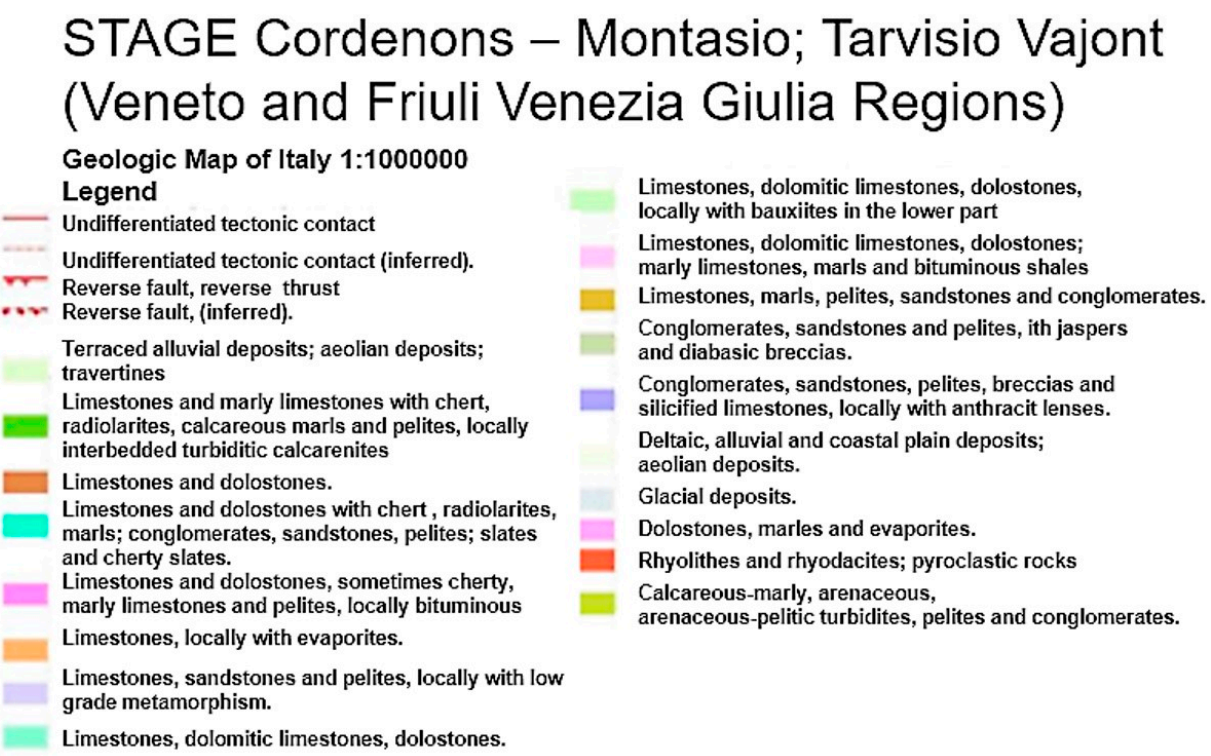

Figure 1. Stages crossing Veneto and Friuli Venezia Giulia Regions (NE of Italy), where the case study is located, represented on the Geologic Map of Italy at the synthetic scale 1:1,000,000. The Vajont site commemorated the landslide tragic event, 50 years later. 


\subsubsection{Dolomites}

Territory, as already noted, is not only a source of risk but also of resources. Not far from the Vajont, the Giro had its classic mountain stages through the Dolomites, which were followed with great interest since they were important for the classification of riders and exciting for their sporting value, as well as for the beautiful landscape through which they passed. This mountain chain, in the north-east of Italy, is a resource, especially for tourism and sports since it draws visitors from all over the world in both summer and winter.

The stages in the Dolomites offered a special chance to observe the spectacular geology of the "pink mountains", UNESCO World Heritage Site [42-46] (Figure 2).

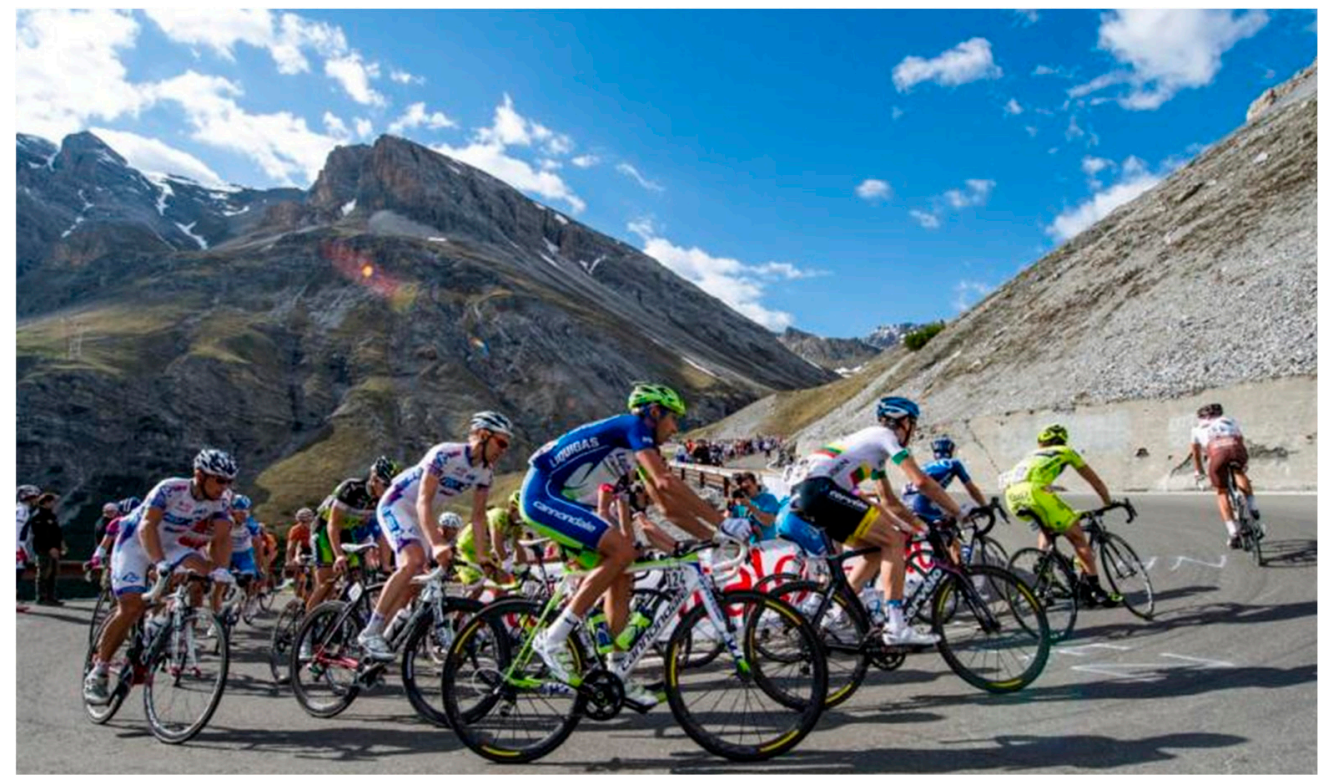

Figure 2. Dolomitic stage Giro d'Italia 2013: WHS, a great territorial resource. The stages in the North East of Italy are strongly representative of the dual Risk/Resource characterizing the Italian country: so beautiful, so fragile.

The final stage of the Giro d'Italia 2013 had its finishing line in "Tre Cime di Lavaredo" (UNESCO World Heritage Site), a "mineral paradise" as defined by the journalist Marco Pastonesi [47], an example of the new and special attention devoted to the environment by the press world.

Considering oneself a living and integral part of the environment in which one lives is a process of fundamental importance in the growth of an individual, of a community, and of society; awareness represents an essential goal and is reachable through an integration of knowledge and conscience. In this sense, environmental protection and public health can be seen as paired together.

\subsection{Towards the Results}

The workflow starts from the premise that divulgation is a way to share knowledge with the aim of activating social behavior in an increasing better one, thanks to consciousness. The knowledge becomes consciousness through experience. We try to teach how to obtain a conscious experience of territory (intended as the result of the integration between nature and culture) making available and comprehensible some scientific concept regarding the natural history of the land. How? Describing Landscape, its components, its evolution: i.e., the natural history of our planet.

The communication has been transmitted during the live TV programs of the most famous Italian cycling Race: the Giro d'Italia, thanks to the popularity of the race, the deep link between cycling races and Landscape, the great diffusion of TV medium. In order to test the effectiveness of the project, we tried to obtain an audience analysis, from both a micro and a macro point of view. On a micro 
level, an informal, dialogic survey has been realized, conducting a semi-structured interview with the members of the public. The selected method is more adequate in those situations such as cycling races are. It is quite impossible to fill out a questionnaire; on the contrary, an informal talk with race spectators, the absence of a rigid protocol and the possibility to change techniques and tools as needs arise, makes it easier to gather data within a flexible context. The selected method is a semi-structured interview conducted with a fairly open framework which allows focused, conversational, two-way communication. In addition, serendipity, intended as the creation of situations in which the researcher can take advantage of chance, can help to find the right approach in talking to the audience [48]. Each set of questions aimed to investigate:

- Personal involvement in cycling and environment (Table 1, Figure 3)

- Personal interest in Sciences (Table 2, Figure 4)

- Personal approach to TV programs (Table 3, Figure 5)

Table 1. Table of personal involvement in cycling and environment.

\begin{tabular}{cccccccc}
\hline Questions & \multicolumn{2}{c}{ Age Range 18-35 } & \multicolumn{2}{c}{ Age Range 35-60 } & \multicolumn{2}{c}{ Age Range $\geq \mathbf{6 0}$} \\
\cline { 2 - 7 } & Yes & No & Yes & No & Yes & No \\
\hline Do you live in this area? & 77 & 23 & 56 & 44 & 72 & 28 \\
Do you use a bicycle rather than car for & 67 & 33 & 53 & 47 & 61 & 39 \\
frequent, short journeys? & 45 & 55 & 71 & 29 & 65 & 35 \\
Are you an amateur cyclist? & 30 & 70 & 15 & 85 & 58 & 42 \\
Have you ever ask to yourself anything about & 30 & 10 & 86 & 14 & 90 & 10 \\
Landscape and natural environment? & 90 & & & & &
\end{tabular}

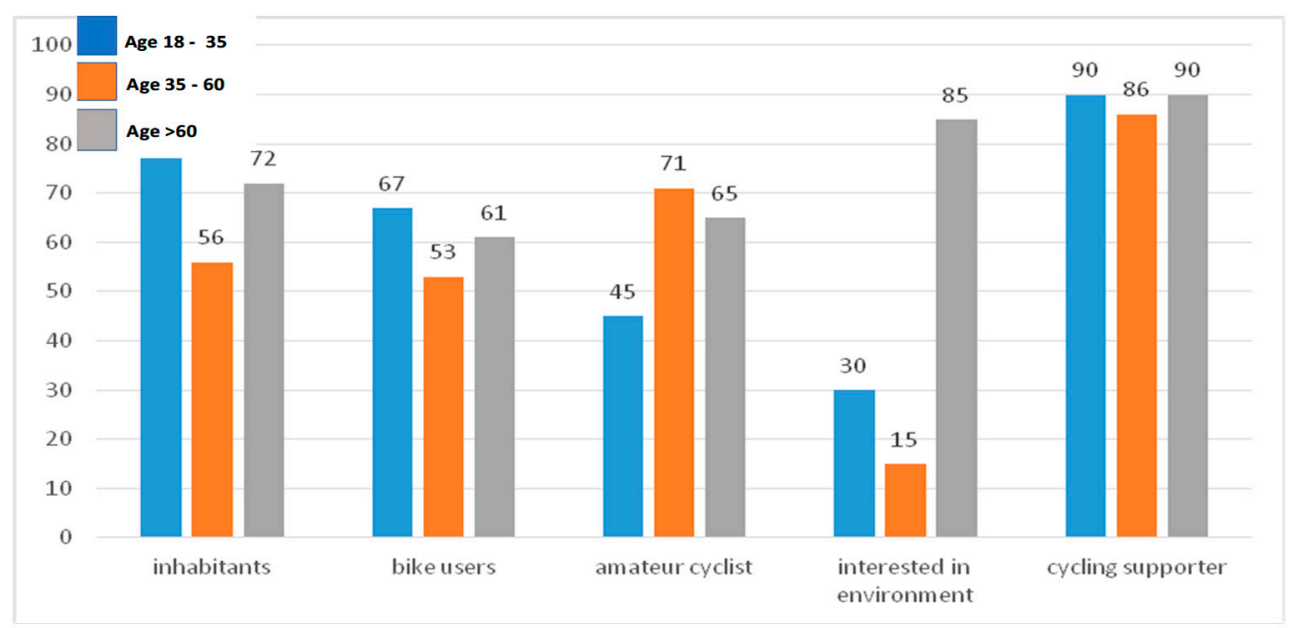

Figure 3. Diagram of personal involvement in cycling and environment.

Table 2. Table of Personal interest in Sciences.

\begin{tabular}{ccccccc}
\hline \multirow{2}{*}{ Questions } & \multicolumn{2}{c}{ Age Range 18-35 } & \multicolumn{2}{c}{ Age Range 35-60 } & \multicolumn{2}{c}{ Age Range $\geq \mathbf{6 0}$} \\
\cline { 2 - 7 } & Yes & No & Yes & No & Yes & No \\
\hline Do you know the GeoloGiro? & 90 & 10 & 88 & 12 & 98 & 2 \\
Do you like it? & 90 & - & 88 & - & 98 & - \\
Were the topics clear and comprehensible? & 90 & - & 88 & - & 98 & - \\
Were the topics interesting? & 90 & - & 85 & - & 98 & - \\
Would you welcome further similar initiatives? & 90 & - & 85 & - & 98 & - \\
\hline
\end{tabular}




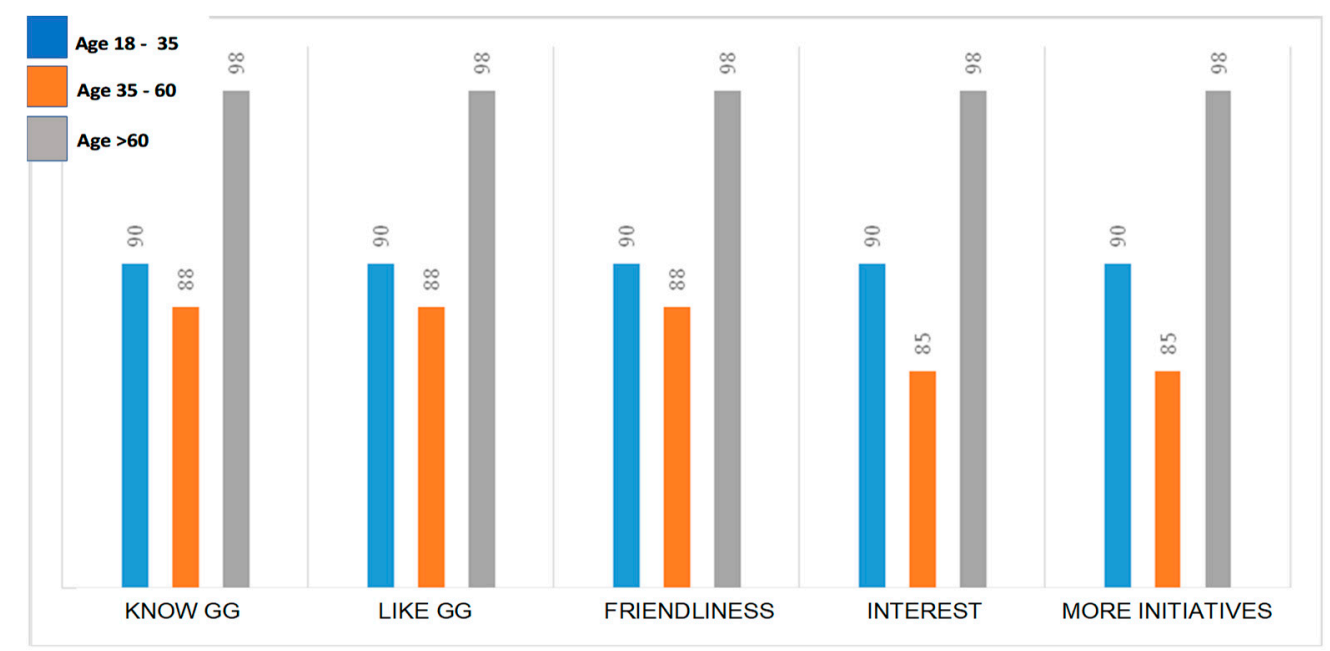

Figure 4. Diagram of Personal interest in Sciences.

Table 3. Table of personal approach to TV programs.

\begin{tabular}{ccccccc}
\hline \multirow{2}{*}{ Questions } & \multicolumn{2}{c}{ Age Range 18-35 } & \multicolumn{2}{c}{ Age Range 35-60 } & \multicolumn{2}{c}{ Age Range $\geq \mathbf{6 0}$} \\
\cline { 2 - 7 } & Yes & No & Yes & No & Yes & No \\
\hline $\begin{array}{c}\text { Do you often watch television? } \\
\text { Do you like TV scientific programs? }\end{array}$ & 86 & 14 & 96 & 4 & 100 & 0 \\
$\begin{array}{c}\text { Would you welcome any new and unconventional } \\
\text { styles in TV scientific communication? }\end{array}$ & 85 & 20 & 80 & 20 & 75 & 25 \\
$\begin{array}{c}\text { Would you welcome any new and } \\
\text { unconventional styles in teaching? }\end{array}$ & 100 & 0 & 81 & & 76 & 4 \\
\hline
\end{tabular}

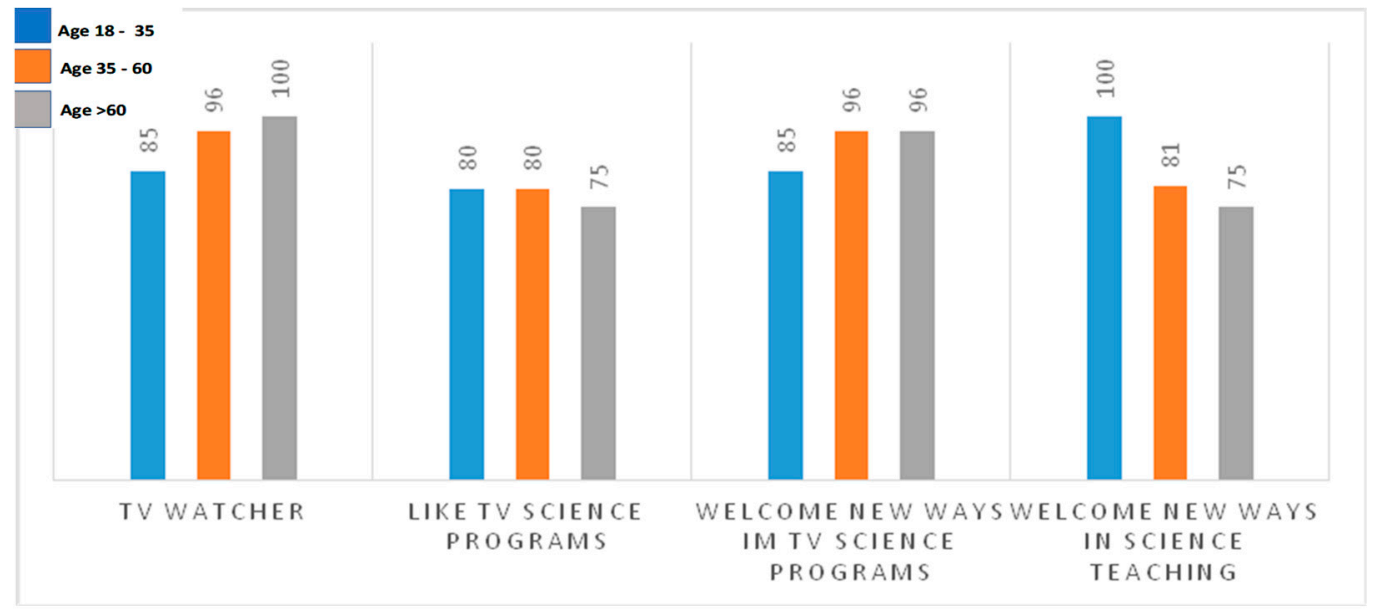

Figure 5. Diagram of personal approach to TV programs.

From a "macro" point of view, the monitoring of the TV audience data gave us further reliable results, as an integration of the "micro" approach [48].

\section{Results and Discussion}

As mentioned in the introduction, the objective of this work consists of finding new methods to spread knowledge. The methodological assumption-based on a holistic approach-and the experience, lead us to implement plans for a concrete popularization of sciences. The information must be assimilated by individual/community/society, in order to become conscious knowledge. The traditional scientific 
communication, such as TV programs too neutral, or too spectacularized, $[49,50]$, has not produced remarkable effects as tools for prevention until now [51,52]: this should make us reflect. The experience in the field has revealed a gap to be filled, a lack of connection between the world of research and that of information. Referring to this sensitive point, Geoethics can provide new suggestions, improving new methods in communication, crossing disciplines, expanding perspectives [53-56]. Therefore, if the idea of GeoloGiro was born from a passion for cycling, its subsequent developments and further articulations of the main idea, are supported by an intuitive understanding of the media scene. Television is the medium popular for excellence, accessible to almost everyone; the great success of reality and talent shows testifies a simple truth: the power of participation and identification. The presence of scientific information in the media is still limited, mainly confined to an area that does not have sufficient exchange with the multiple communication channels. Even codes and styles of the proposals remain static in a format that often fades to spectacolarization or myth, subtracting reliability from the scientific truth. The knowledge becomes science through encoding processes that make it universal. But code-sharing is bound to a restricted number of users; therefore, it should be made available again through re-adaptation operations codes. It is essential the function of the informative vectors that make the information accessible.

The difficulty is in finding distribution channels: the acceptance of projects based on the integration of different disciplines is not easy. In the science field, the so-called contamination, is considered more for a negative sense of the term, rather than in the creative sense given to the term by an artistic point of view. Yet the world of research has recently offered new proposals-scientifically based-to the media world [57-59]. In this context, the GeoloGiro provided reliable results, because of continuous documentation by audience data RAI. The fact itself of having opened a constantly progressing space, in a world seemingly far away, but more than ever connected to common themes, has been a success. But the consolidation of the results and the evolution of the project, require constant and direct presence, and flexibility as well. The fusion of Sport and Territorial Sciences s.l., is likely to have unexpected effects; in particular, it can reach a segment of the public until now marginalized, creating a new base, crucial in participation in a real action to protect the environment and self-civil protection.

\section{Evaluation of the Achieved Results}

Regarding the analysis of results, it is necessary to analyze long-term results, surveying many components in social behavior, extending the inquiry to a wide and varied range of pubic. Here are explained some of the criteria used in organizing and testing the research. With the aim to testing public reactions, some spectators following the race on the road have been interviewed in an informal, participative way. The sample is divided into three ranges, based on age. The questions can be grouped into three categories: personal involvement in cycling and territory; personal interest in the project; personal style in watching television. The answers are expressed as a percentage. A further diagram (Figure 6) shows the audience distribution, linking interviewed spectators to Italian geographical Macro-Areas (North, Center, South and Islands), during the last six editions of the race (years 2012-2017).

A further evaluation of the achieved results can be reached by analyzing the audience data, measured by Auditel: the official method for TV audience measurement in Italy. The method is based on statistical tools, setting up a panel of families representing the Italian population as a whole. The selection guarantees a wide range of geographic, demographic and sociocultural characteristics, by using a wide panel size ( 20,000 people in 1700 municipalities). An electronic tool, the so called "meter" measures every day, the audience, of each TV by the selected families. Nothing is lost with the meter that automatically records every change of channel. The method also guarantees a correct representation of the population's structure, by adopting a weighting by cell system according to which the total of the expansion factors of each individual coincides with the universe of various 
groups of the individual population (more than 200 groups) and, obviously, with the total of the considered population.

During the last years, media have deeply changed so the Auditel system is no more exhaustive in analyzing the audience. Moreover, referring to cycling, it is necessary to consider the huge public following the races on the road.

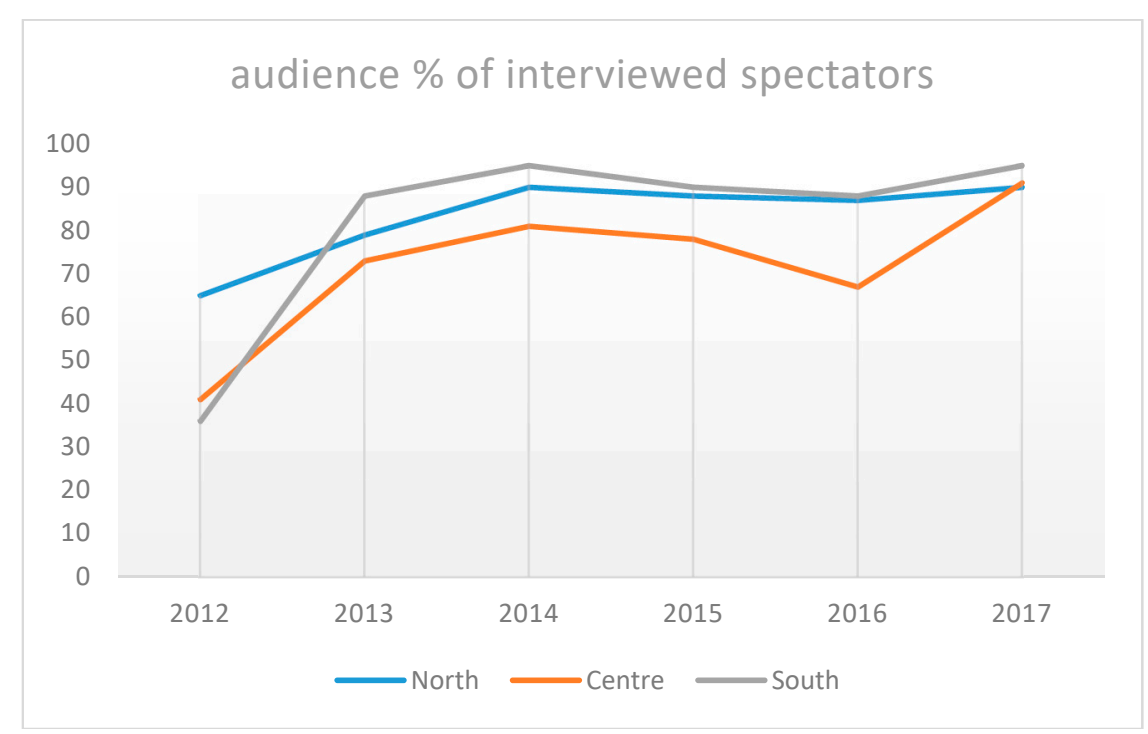

Figure 6. Percentage audience of interviewed cycling supporters, linked to Italian Macro-Areas.

Figure 7 links the TV Auditel share to each stage: the maximum peaks correspond to the most important stages of the Giro, the high mountain ones, mostly at the end of the competition.

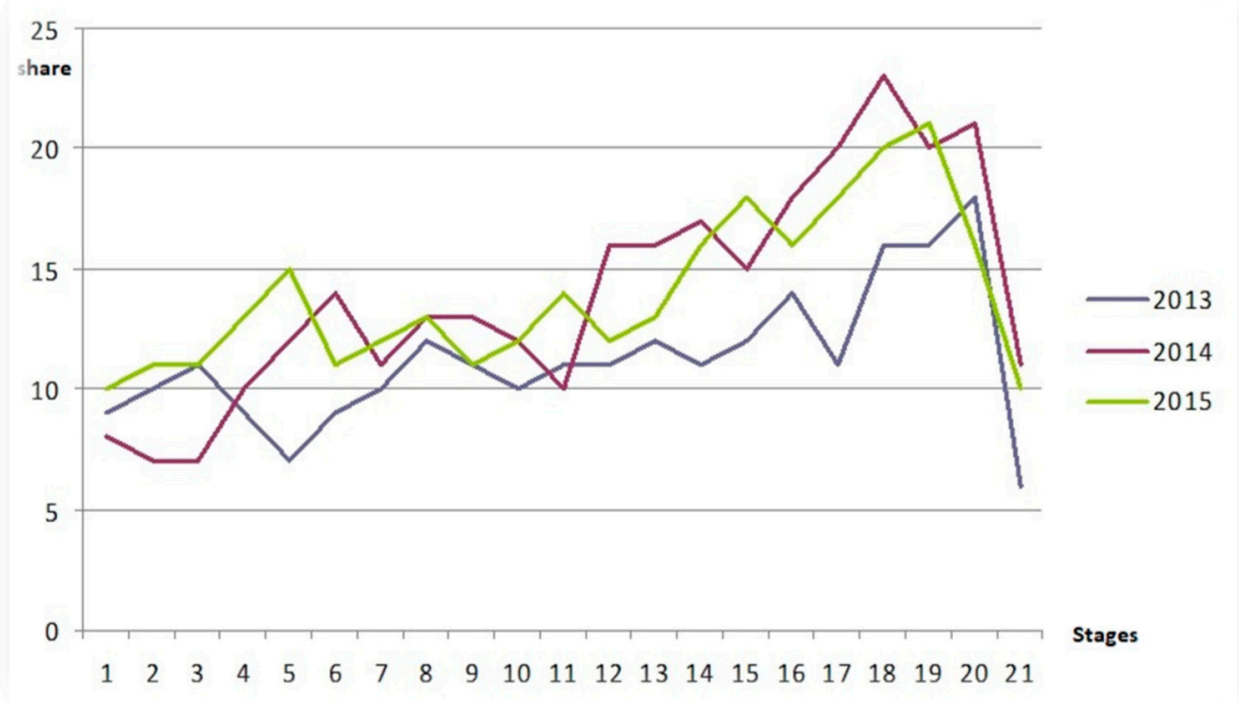

Figure 7. TV Auditel share/stages of the Giro.

The audience represented in Figure 8, linking the share of the various live TV transmissions during the same stage, better shows the approval reached by the project. The time band dedicated to "Anteprima Giro" has obtained an increasing audience. 


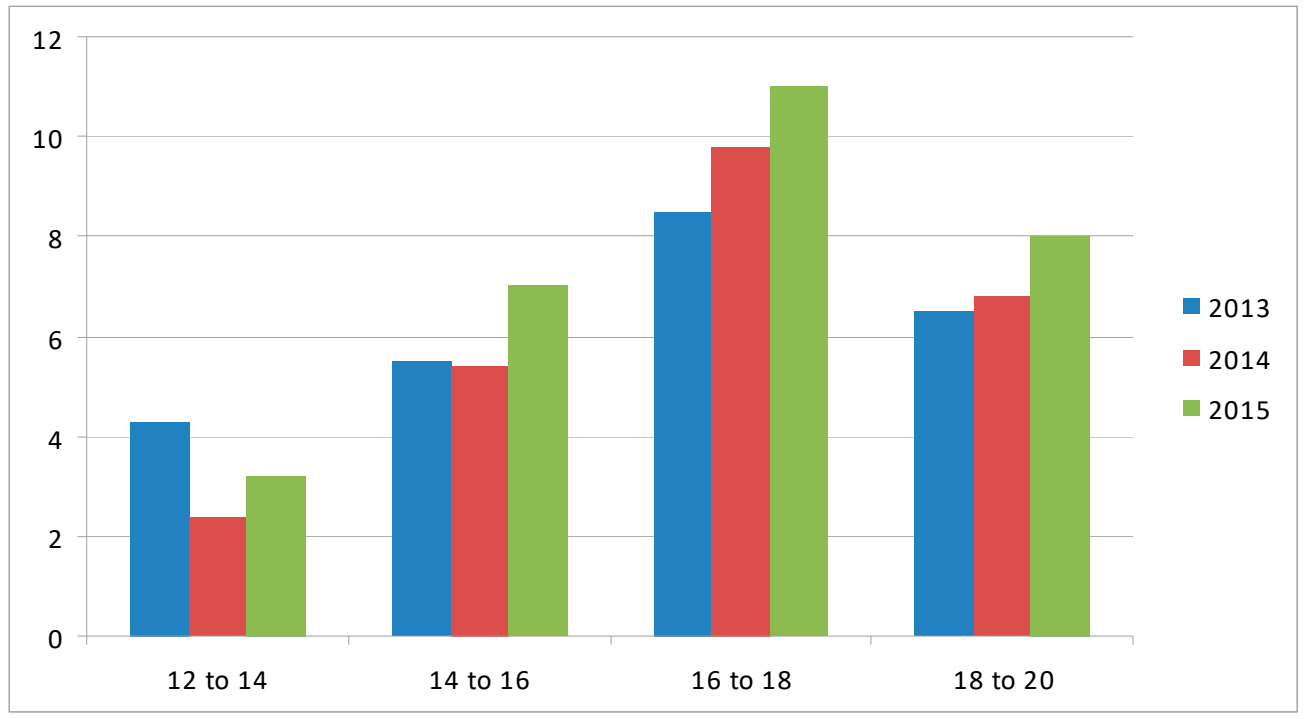

Figure 8. Time band/TV Auditel Share.

The interrelation between the audience data and the contents of the program transmitted during the time band from $14 \mathrm{pm}$ to $16 \mathrm{pm}$ must be interpreted referring to more indicators, obtained by following a qualitative method of the GeoloGiro experiences [60].

The effectiveness of the "GeoloGiro" project is confirmed by its ability to reach a vast audience, something that is unimaginable for the traditional forms of scientific communication, The fact that the television public might not be concentrated on the minutes dedicated to prevention of environmental risks is compensated by the continuity of the transmission over 4 weeks (the duration of the race), and this broadens the possibility of exposure to a specific communicative fragment on air between 2 and 3 p.m. during the live broadcast of the stage.

On the other hand, it is not easy to analyze audience data to find information about the effectiveness of the communication for the aims of prevention. The desired success in this sense can only be measured by an actual evolution of social behaviour, and to this end it is necessary to make observations and studies over long time intervals. In the meantime, we can obtain important information from some significant indicators.

Particularly interesting is the intergenerational nature of the audience; indeed the time slot around lunch time and immediately preceding the most important competitive phase of the stage, means that there are both elderly and young viewers. Very often it is the elderly who talk about the slot dedicated to the environment and prevention, thus favoring the diffusion of the information in the family setting. Moreover, old people are the most sensitive in recognizing the territory, a sign of experience of times when life was closely tied to the environment. The inductive effect activated by the transversality of the audience is very important in involving "distracted" interlocutors in the spread of information.

Another essential element is the continuity of the project. The fact that the presence of a geologist on the mobile stage of the Rai Sport (www.raisport.rai.it/) broadcast of the Anteprima Giro from 2012 to the present, displays without a doubt the validity of the project from the point of view of the media.

The results "in the field" are very encouraging. The race and stages have a large following, and the ways of involving this audience in the race favor direct contact between spectators and those working on the race. This is another important element-as told before-to be there in person and to talk directly on TV and with the people on the ground, in other words working in the open and putting oneself on the line. It is only in this way that geologists can become ambassadors of a project and can be recognized for the message it transmits, conferring credibility to the project's mission.

There is much direct evidence to support this from the people met along the route. In many occasions the "geologist of the Giro" was stopped and asked specific information about the state of 
the security of the territory. This is an important result, because the profession of geology is largely unknown in Italy.

The response to the project has been positive also in the pressroom. The most significant testimonials have been published by the great names of sporting journalism: Marco Pastonesi of the "Gazzetta dello Sport" (the daily sports newspaper that organizes the race) inserted some comments about the environmental characteristics of the stages in his articles, [47] while Eugenio Capodacqua of the "La Repubblica" (one of the most authoritative daily national newspapers) interviewed the geologist about the state of prevention of hydrogeological instability in Italy [61].

But the most comprehensive synergy was provided by the "Repubblica delle Biciclette" a sport web site, which published online the complete documentation about the stages (information about the environment, territory, risk and prevention).

In the scientific setting, ISPRA's Geological Survey shared the project in its 2014 edition, including the educational material and the 3D videos that were shown during the live TV broadcasts, the complete series of the live TV talk show [62] on its institutional site (www.isprambiente.gov.it/). The data showed significant access by other scientists and researchers in some way tied to the activities of the institute (Figure 9). This sharing of information is a significant and positive result as too often research groups regard unconventional projects with wariness.

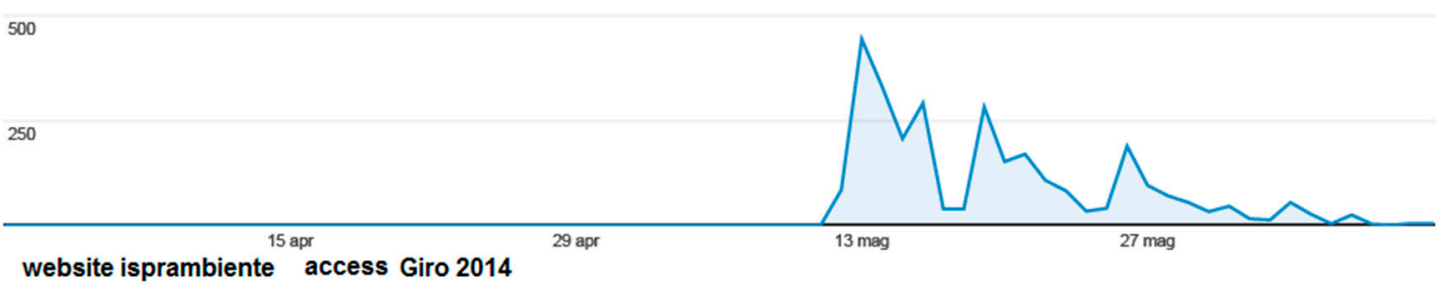

Figure 9. The picture shows the number of times the ISPRA institutional website was accessed, referring to the 3D videos of the Giro d'Italia 2014 and the related information, published contemporariously with the race.

The experience of the Giro has given the green light for other modes of scientific information given directly on the ground such as during the Gran Fondo Roma race and the Calanchi Marathon. In the latter, the sporting race was accompanied by a series of events such as a guided excursion to the Riserva dei Calanchi di Montalbano Jonico (particular geological structures formed by an accelerated erosion of clay slopes) showing how landscapes can be represented in the risk/resources balance towards the favourable element of resources thanks to a wise management of an area.

Last but not least, our project was given the satisfaction of the attention and curiosity of sporting champions of the recent past, often guests during the TV transmission and sporting commentators. One of them, Davide Cassani, who is now coach of the national road cycling team, has become the testimonial of the GeoloGiro experience.

\section{Conclusions}

In the so-called postmodern world, a plethora of tools and sources offers everyone around the world the possibility of participating in social dynamics, a resulting side effect of which is an extreme superficiality and fragmentation of knowledge.

At the same time, the concept of sustainability has come to the fore as an indispensable response to the effects on our planet of development that continues at an exponential rate and in an often unpredictable manner $[63,64]$.

A possible solution of the disconnect between progress, its side effects and society, is a shared awareness, and this can only be reached through knowledge provided by science. 
The holistic approach finds a fertile terrain of application and favors a plurality of points of view that is the only valid way to knowledge, through recognition of one's own attitudes and capacity of integrating those of others.

A preventive behavior is certainly the best tool in the field of environmental protection and public health. A goal that is achieved thanks to the change of behavior, a process that matures through the assimilation of knowledge as well as the acquisition of shared awareness.

Prevention of environmental risk, as an extension of public health, must be taught and widely spread. Prevention is a combination of knowledge, conscience, and action. Until it is assimilated and transformed in behaviour, it is essential to work on many fronts. Information is the first and most vital step. While scientific communication must be simple, scientific information must not be simplified; it is a question of language that must be rendered comprehensible. The presence of information must be constant and offered to the general public without it having to seek it out, and at the same time it must be very good so as to instill trust and familiarity.

A balanced approach is needed to make known risks and resources, providing technical and cognitive tools. We must consider it a campaign of prevention in the field of health. Those such as the campaigns against smoking, alcohol, drugs and in favour of road safety, that used fear as the main motivation have been shown to not always be effective. This is because of an altered perception of risk, based on the following: a sense of omnipotence (youth), distraction by other problems (adults), and resignation (elderly). The most common reaction is: "it already happened to someone else, so it won't happen to me". Moreover, in Italy there is a widespread sense of fatalism tied to religious tradition.

The approach we propose is new and is based on cognitive-behavioural mechanisms that are activated by recognition of something (landscape) that we are tied to a reciprocal belonging or ownership. Its application in a sporting context, as the cycling races are, confers a greater credibility of the message and a greater effectiveness to the process. Referring to cycling, it is important to underline the new attention paid to promoting clean athletes in a clean environment. That is a further reason why two different worlds help each other in an ethic mission.

These proposals would provide sport in general with greater educational potential and would provide cycling with a stronger stance from which to revalidate its nature as a healthy and sustainable sport.

The youngest generation is the focus of desirable and necessary dynamics for change; they are a starting place for a new active approach to science and its applications, a catalyst for the process of engagement of the "facies sociale" of adults, leaders and people responsible for the current state of affairs, yet far too often deprived of future prospects and conditioned by the obsession of the "here and now".

We strongly believe, following years of experience first in teaching, then in research and finally in scientific communication, that it is necessary to build a bridge between diverse realities and between diverse communicative codes. This is an essential geoethic objective.

Appealing to themes that best embrace the collective imagination, such as cycling, is therefore profoundly motivated as it facilitates phenomena of identification and engagement. It responds to the need to arouse curiosity and vision, which lead to the planning and realization of a polyhedral objective thanks to teamwork.

There are few similar experiences referred to Earth Sciences, divulged to the public during and through cycling races, although the natural environment of the competition is quite the real natural environment. To be fair, there is a parallel, contemporary initiative, published on the Tour de france 2012 web site, "L'oeil du geologue" that showed to the public some relevant geosites of the Tour stages. The experience has been followed by a book [63]. Further analogues experiences in the field, following the Italian example, were realized at the Tour 2016 and at the Vuelta de España 2016 and 2017 [64]. Future European initiatives will start next year in a coordinate manner, within an EFG project. The communicative methods will be inspired by the format here proposed, considering originality, continuity and multimediality of the experiences realized at the Giro d'Italia. Territorial 
and environmental problems demand, now more than ever, and particularly in our country, where the situation is dramatic, the constant presence of the geologist in all social, cultural, economic and territorial contexts. Following the philosophy of the project, one can compare the geologist to the medical doctor [65], that is, we must leave the offices, laboratories, and teaching halls and go and talk to the people $[66,67]$.

From the latest events (the earthquakes in the center of Italy) emerged the need to create a new kind of communication, providing society with correct and clear information: a common action, aimed at making comprehensible to the whole society, which is the role of Earth dynamics and can be considered an ethic mission.

Expanding on Khalil Gibran's idea "your house is your larger body" [68], we say that our territory is our larger house.

Acknowledgments: The authors wish to thank Sarah Morgan and Alessio Baccarini for the manuscript revision and Michele Lugeri, Nicola Lugeri, and Fabrizio Galluzzo for their participation in the project GeoloGiro.

Author Contributions: Francesca Romana Lugeri conceived and designed the experiments; Francesca Romana Lugeri and Piero Farabollini performed the experiments; Piero Farabollini, Vittorio Amadio and Roberto Greco analyzed the data; Francesca Romana Lugeri and Roberto Greco wrote the paper.

Conflicts of Interest: The authors declare no conflict of interest. The founding sponsors had no role in the design of the study; in the collection, analyses, or interpretation of data; in the writing of the manuscript, and in the decision to publish the results.

\section{References}

1. Bohle, M.; Ellis, E.C. Furthering Ethical Requirements for Applied Earth Science. Ann. Geophys. 2017, 1-6. [CrossRef]

2. Peppoloni, S.; Di Capua, G. Geoethics: Ethical, social, and cultural values in geosciences research, practice, and education. In Geoscience for the Public Good and Global Development: Toward a Sustainable Future; Wessel, G.R., Greenberg, J.K., Eds.; Geological Society of America: Boulder, CO, USA, 2016; pp. 17-21, ISBN 978-0-8137-2520-8.

3. Vasconcelos, C.; Vasconcelos, L.; Torres, J. Education and Geoethics: Three Fictional Life Stories Geoscience Education; Springer: Berlin, Germany, 2016; pp. 225-236.

4. Peppoloni, S.; Di Capua, G. Geoethics and geological culture: Awareness, responsibility and challenges. Ann. Geophys. 2012, 55, 335-341.

5. Martínez-Frías, J.; González, J.L.; Pérez, F.R. Geoethics and deontology: From fundamentals to applications in planetary protection. Episodes 2011, 34, 257-262.

6. Wyss, M.; Peppoloni, S. Science Geoethics: Ethical Challenges and Case Studies in Earth Sciences; Elsevier: Amsterdam, The Netherlands, 2014; pp. 3-13.

7. Vasconcelos, C.; Torres, J.; Vasconcelos, L.; Moutinho, S. Sustainable Development and its Connection to Teaching Geoethics. Episodes 2014, 39, 509-517. [CrossRef]

8. Di Capua, G.; Peppoloni, S. Geoethical Aspects in the Natural Hazards Management. In Engineering Geology for Society and Territory; Lollino, G., Arattano, M., Giardino, M., Oliveira, R., Peppoloni, S., Eds.; Springer International Publishing: Basel, Switzerland, 2014; Volume 7, pp. 59-62.

9. Matteucci, R.; Gosso, G.; Peppoloni, S.; Piacente, S.; Wasowski, J. The Geoethical Promise: A Proposal. Episodes 2014, 37, 190-191.

10. Abel, O.; Varet, J. Global approach to geoethics: A first attempt. In Proceedings of the Mining Pribram Symposium, the International Section, Geoethics, Pribram, Czech Republic, 15-19 October 2017.

11. Beck, U. Risikogesellschaft: Auf dem Weg in eine Andere Moderne [The Risk Society: Towards a Second Modernity]; Suhrkamp Verlag F: Frankfurt, Germany, 1986; p. 33.

12. International Year of Planet Earth 2007-2009. Available online: http://www.yearofplanetearth.org/ (accessed on 11 December 2017).

13. 2017 International Year of Sustainable Tourism for Development. Available online: http://www. tourism4development2017.org/ (accessed on 12 December 2017). 
14. EEA Report No 13/2016: Communication, Environment and Behaviour. Available online: https:/ /www.eea. europa.eu/publications/communication-environment-and-behaviour (accessed on 12 December 2017).

15. Barca, F. Territorio e Coesione-EDIESSE; Ediesse: Roma, Italy, 2017; pp. 12-13.

16. Putini, A. Esperimenti di Democrazia; Aracne: Roma, Italy, 2011; p. 128.

17. Sieber, R. Public Participation Geographic Information Systems: A Literature Review and Framework. Ann. Assoc. Am. Geogr. 2006, 96, 491-507. [CrossRef]

18. McKinster, J.; Trautmann, N.; Barnett, M. Teaching Science and Investigating Environmental Issues with Geospatial Technology: Designing Effective Professional Development for Teachers; Springer Science \& Business Media: Berlin, Germany, 2013; p. 353.

19. Farabollini, P.; Lugeri, F.R.; Amadio, V.; Aldighieri, B. The role of Earth Sciences and Landscape Approach in the Ethic Geology: Communication and Divulgation for the Prevention and Reduction of Geological Hazards. In Engineering Geology for Society and Territory; Lollino, G., Arattano, M., Giardino, M., Oliveira, R., Peppoloni, S., Eds.; Springer: Heidelberg, Germany, 2014; Volume 7, pp. 115-120.

20. Lugeri, F.R.; Farabollini, P.; Graziano, G.; Amadio, V. Nature and culture in a landscape approach. Eur. Geol. 2012, 34, 23-28.

21. Council of Europe. European Landscape Convention; European Treaty Series, No. 176; Council of Europe: Strasbourg, France, 2000; pp. 2-4.

22. Troll, C. Die Geografische Landschaft und Ihre Erforschung; Springer: Heidelberg, Germany, 1950; pp. $163-181$.

23. Forman, R.T.T.; Godron, M. Landscape Ecology; Wiley: New York, NY, USA, 1986; p. 620.

24. Naveh, Z.; Lieberman, A. Landscape Ecology Theory and Application; Series on Environmental Management; Springer: New York, NY, USA, 1994; pp. 99-103.

25. Badiali, F.; Piacente, S. The study of the landscape: From a holistic approach to a social concept of knowledges. Ann. Geophys. 2012, 55, 481-485.

26. Kawulich, B.B. Participant observation as a data collection method. Forum Qual. Soc. Res. 2006, 6. [CrossRef]

27. James, P. Spradley Participant Observation; Waveland Press: Long Grove, IL, USA, 2016; p. 195.

28. Devereux, E. Understanding the Media; Sage Publication: Twelve Oaks, CA, USA, 2003; p. 86.

29. Crutzen, P.J. The "Anthropocene". In Earth System Science in the Anthropocene; Ehlers, E., Krafft, T., Eds.; Springer: Berlin/Heidelberg, Germany, 2006; pp. 3-6.

30. Farabollini, P.; Graziano, G.; Lugeri, F.; Lugeri, M.; Lugeri, N. Paesaggio, Ambiente naturale e culturale in un approccio sistemico per la divulgazione delle Geoscienze. In Geologia Tecnica \& Ambientale; Consiglio Nazionale dei Geologi: Roma, Italy, 2013; Volume 1, pp. 64-75.

31. Catton, W.R., Jr.; Dunlap, R.E. Environmental Sociology. A New Paradigm. Am. Sociol. 1978, 13, 41-49.

32. Pellizzoni, L.; Osti, G. Sociologia Dell'ambiente; Il Mulino: Bologna, Italy, 2003; p. 29.

33. Amadio, V. Analisi di Sistemi e Progetti di Paesaggio; Franco Angeli: Milano, Italy, 2003; p. 23.

34. Nettleton, K.F. Cases on 3D Technology Application and Integration in Education; IGI Global: Hershey, PA, USA, 2013; p. 359.

35. Lugeri, F.; Muciaccia, M. Landscape approach and GIS: New ways in teaching Territorial Sciences. In Conference Proceedings. The Future of Education; Pixel libreriauniversitaria.it Edizioni: Padua, Italy, 2016; pp. 216-221.

36. Lugeri, F.R.; Lugeri, N.; Graziano, G.V.; Farabollini, P.; Amadio, V. The 3D GeoloGiro. In Proceedings of the 8th EUREGEO EUropean Congress on REgional GEOscientific Cartography and Information Systems, Bologna, Italy, 15-17 June 2015; Barcelona Institut Geologic Cartografic de Cataluña: Barcelona, Spain, 2015; pp. 59-63.

37. McFall, B.C.; Mohammed, F.; Fritz, H.M. Physical Modeling of Landslide Generated Tsunamis and the 50th Anniversary of the Vajont Dam Disaster, EGU General Assembly Wien. 2013. Available online: http:/ / adsabs.harvard.edu/abs/2013EGUGA.1512984M (accessed on 27 October 2017).

38. Panizzo, A.; De Girolamo, P.; Di Risio, M.; Maistri, A.; Petaccia, A. Great landslide events in Italian artificial reservoirs. Nat. Hazards Earth Syst. Sci. 2005, 5, 733-740. [CrossRef]

39. Genevois, R.; Ghirotti, M. The 1963 Vaiont Landslide. J. Appl. Geol. 2005, 1, 41-53.

40. Besio, M. Hydrogeological notes regarding mount Toc and vicinity. In Proceedings of the Convegno Sulla Frana del Vaiont, Ferrara, Italy, 17-19 September 1986.

41. Semenza, E.; Ghirotti, M. History of the 1963 Vaiont slide: The importance of geological factors. Bull. Eng. Geol. Environ. 2000, 59, 87-97. [CrossRef] 
42. Panizza, M.; Piacente, S. Geomorfologia Culturale; Pitagora: Bologna, Italy, 2003; p. 350.

43. Panizza, M. The Geomorphodiversity of the Dolomites (Italy): A Key of Geoheritage Assessment (Published in Geoheritage 2009). Available online: https:/ / doi.org/10.1007/s12371-009-0003-z (accessed on 31 December 2017).

44. Panizza, M. Nomination of the Dolomites for inscription on the World Natural Heritage List UNESCO. In Landscapes and Landforms of Italy; Soldati, C.d.M., Marchetti, M., Eds.; Springer: Berlin, Germany, 2017; pp. 7-20.

45. Doglioni, C. Tectonics of the Dolomites. Bull. Angew. Geol. 2007, 12, 11-15.

46. Bosellini, A.; Doglioni, C. Progradation geometries of Triassic carbonate platforms of the Dolomites, and their large-scale physical stratigraphy. In AAPG Field Trip in the Dolomites; American Association of Petroleum Geologists: Tulsa, OK, USA, 1988.

47. Pastonesi, M. Pane e Gazzetta. 2013. Available online: paneegazzetta.gazzetta.it/ (accessed on 12 December 2017).

48. Participatory Survey Methods for Gathering Information. Available online: http://www.fao.org/docrep/ w8016e/w8016e01.htm (accessed on 18 December 2017).

49. Cook, T.D.; Curtin, T.R. An Evaluation of the Models Used to Evaluate Television Series. In Public Communication and Behavior; Comstock, G., Ed.; Academic Press: Cambridge, MA, USA, 1986; pp. 1-64, ISBN 9780125319560.

50. Hearold, S. A Synthesis of 1043 Effects of Television on Social Behavior. In Public Communication and Behavior; Comstock, G., Ed.; Academic Press: Cambridge, MA, USA, 1986; pp. 65-133, ISBN 9780125319560.

51. McGuire, W.J. The Myth of Massive Media Impact: Savagings and Salvagings. In Public Communication and Behavior; Comstock, G., Ed.; Academic Press: Cambridge, MA, USA, 1986; pp. 173-257.

52. Unifpa-United Nations Population Fund. Technical Support Division (TSD) Communication/Behaviour Change Tools Programme Briefs No. 1 Entertainment-Education January 2002. Available online: http: / / www.unfpa.org/ (accessed on 30 September 2017).

53. Phillips, J. Storytelling in Earth Sciences: The Eight Basic Plots Earth-Science Reviews; Elsevier: Amsterdam, The Netherlands, 2012; pp. 153-162.

54. Martin, K.; Miller, E. Storytelling and Science-Language Arts; JSTOR: New York, NY, USA, 1988; pp. 869-1034.

55. Allan, M. Geotourism: An Opportunity to Enhance Geoethics and Boost Geoheritage Appreciation, Geological Society, London, Special Publications. 2015. Available online: http://www.lyellcollection. org/cc/open-access-collection (accessed on 27 October 2017).

56. Dahlstrom, M.F. Using Narratives and Storytelling to Communicate Science with Nonexpert Audiences. Proc. Natl. Acad. Sci. USA 2014, 111, 13614-13620. [CrossRef] [PubMed]

57. Hanson, R.E. Mass Communication: Living in a Media World, 6th ed.; CQ Press: Washington, DC, USA, 2016; p. 488.

58. Foresta Martin, F.; Peppoloni, S. Geoethics in Science Communication: The Relationship between Media and Geoscientists. Ann. Geophys. 2017, 60,1-6.

59. Kerski, J.J. Geo-Awareness, Geo-Enablement, Geotechnologies, Citizen Science, and Storytelling: Geography on the World Stage-Geography Compass; Wiley Online Library: Hoboken, NJ, USA, 2015; pp. 14-26.

60. Emerson, R.M.; Fretz, R.I.; Shaw, L.L. Participant Observation and Fieldnotes. In Handbook of Ethnography; Atkinson, P., Coffey, A., Delamont, S., Lofland, J., Lofland, L., Eds.; Sage Publications: Thousand Oaks, CA, USA, 2001; pp. 356-357.

61. Capodacqua, E. A Ruota Libera 2013. Available online: capodacqua.blogautore.repubblica.it/ (accessed on 27 October 2017).

62. 4a Tappa I Nacer Bouhanni. Available online: http://www.raisport.rai.it/dl/raiSport/media/4-Tappa-Nacer-Bouhanni-31a336b9-aa91-48bb-b82e-ec177ad610fc.html (accessed on 30 August 2017).

63. François, M. Le Tour de France d'un Géologue; BRGM Group: Orléans, France, 2012; pp. 98-99.

64. Geodiversity. Available online: http://www.lavuelta.com/la-vuelta/2017/es/geodiversidad/ (accessed on 1 January 2018).

65. Miccadei, E. Didattica, Geologia e Turismo. 2015. Available online: http:/ / www.icpalenatorricella.gov.it/ icpalena/ (accessed on 14 September 2017).

66. Bowser, G.; Gretzel, U.; Davis, E.; Brown, M. Educating the Future of Sustainability. Sustainability 2014, 6, 692-701. [CrossRef] 
67. Odukoya, J.A.; Ebenezer, B.; Okunlola, S. Social Impact of Mobile Learning Tablets on Education and Sustainable Development: Evidence from a Private Nigerian Tertiary Institution. In Booth Sustainable Development and Planning IX; Brebbia, C.A., Longhurst, J., Marco, E.C., Eds.; Conference Paper; WIT Press: Ashurst, UK, 2017; p. 862.

68. Gibran, K. Il Profeta; Alfred A. Knopf: New York, NY, USA, 1923.

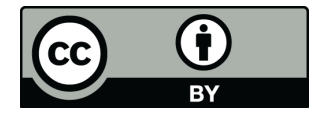

(c) 2018 by the authors. Licensee MDPI, Basel, Switzerland. This article is an open access article distributed under the terms and conditions of the Creative Commons Attribution (CC BY) license (http:/ / creativecommons.org/licenses/by/4.0/). 